\title{
The Behaviour of Meiotic Chromosomes in Leek, $A$. porrum L.
}

\author{
M. K. Wajahatullah* \\ Department of Genetics, University of Birmingham, Edgbaston, \\ Birmingham B15 2TT, England
}

Accepted July 8, 1994

Leek is an out-breeding biennial, grown chiefly for its leaf bases and green leaves that are used as food. Allium porrum has been worked out cytologically (Levan 1940, Kadry and Kamel 1955, Murin 1964). The chromosome count known for wild leek (A. ampeloprasum) was done by Darlington and Wylie (1956). It is not clear yet whether it is autotetraploid or allotetraploid but is generally considered an autotetraploid (Levan 1940, Kadry and Kamel 1955, Murin 1964). Currah (1986) has pointed out the difference between the auto- and allo-polyploid state. This paper deals with metaphase-I chromosome behaviour in $A$. porrum with particular reference to configurations (IIs, IVs, Is, etc.), chiasma frequency, chiasma distribution, micronuclei and microcell frequencies.

\section{Materials and methods}

A. porrum L. used in the present study was kindly supplied by Dr. B. Smith, Horticulture Research International, Wellesbourne, UK. The varieties used were Alaska, Winterreuzen, King Richard, American flag and Lyon. Fresh buds of size 1-2 inches were collected in distilled water just before use. Temporary slides were made by squashing anthers in $1.8 \%$ aceto-orcein stain and were sealed with "Holdtile" rubber glue to avoid drying. Numbers and locations of chiasmata in well spread metaphase-I cells were scored. Locations of chiasmata were categorised into very proximal (VP), proximal (P), interstitial (I) and distal (D) as shown in Fig. 1. Chromosomal configurations in terms of bivalents, univalents, quadrivalents were scored at metaphase-I. Micronuclei and microcells at tetrad stage were also recorded. All the analyses were carried out by statistical package Minitab release-7.2.

\section{Results and discussion}

The chromosome count in all the cells was $2 n=4 x=32$ which is in agreement with the previous workers (Levan 1940 in A. porrum, Darlington and Wylie 1956 in A. ampeloprasum). Koul and Gohil (1970) have also observed the same number in $A$. ampeloprasum which is like cultivated leek as described by Jones and Mann (1963). No B-chromosomes were observed, however, Nybom (1947) and Vosa (1966) did observe B-chromosomes in A. porrum. Most of the cells showed chromosomal association in the form of 32 IIs. Among the other associations

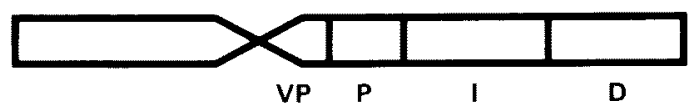

Fig. 1. Diagrammatic representation of the distribution of very-proximal (VP), proximal (P), interstitial (I) and distal (D) chiasmata.

\footnotetext{
* Present address: Nuclear Institute for Agriculture and Biology (NIAB), PO Box 128, Faisalabad, Pakistan.
} 
30 IIs with 2 Is and 28 IIs with 1 IV were observed.

\section{Chiasma frequency}

The mean chiasma frequency ranged between $30.14-30.5$ per cell. The maximum mean chiasma frequency was observed in variety Lyon (30.5) and lowest (30.14) in Winterreuzen and King Richard (Table 1). In most of the cells, fifteen bivalents with two chiasmata and one bivalent with one chiasma were commonly observed. There was no considerable difference for chiasma frequency between and within the varieties which indicates uniformity and lack of variation between five varieties of $A$. porrum.

\section{Chiasma distribution}

Differentiation between individual bivalents was difficult as all the bivalents were of median size except two small and two large bivalents. Most of the observed chiasmata (96$100 \%$ ) were very-proximally (Fig. $2 \mathrm{a}$ ) or proximally (Fig. $2 \mathrm{~b}$ ) localized but a low frequency $(0.19-0.31 \%)$ of non-proximal (interstitial and distal chiasmata) were also found. The highest frequency $(97.25 \%)$ was of very-proximal chiasmata and was observed in variety American flag while the lowest (52.13\%) was observed in King Richard. King Richard also showed a high percentage $(57.86 \%)$ of non-very proximal chiasmata. Interstitially localized chiasmata
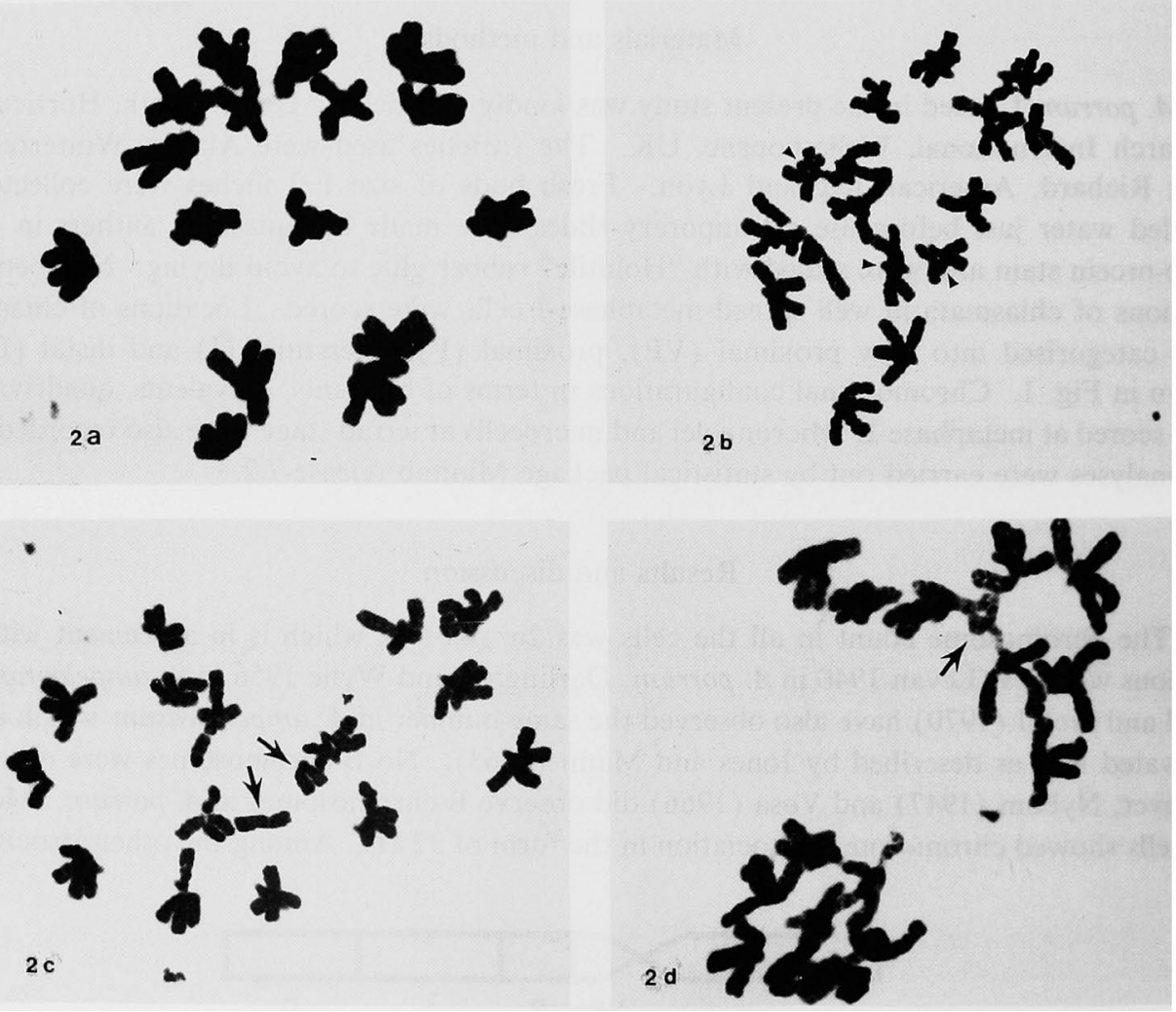

Fig. 2a-2d. 2a. Metaphase-I of $A$. porrum, showing very proximal localization of chiasmata. 2b. Chromosomes of $A$. porrum at metaphase-I (arrows indicate proximally localized chiasmata). 2c. Metaphase-I of $A$. porrum with 14 IIs and Is (arrows indicate univalents). 2d Metaphase-I in

$A$. porrum with 12 IIs and a quadrivalent resulting from distally localized chiasma (arrow indicating quadrivalent). $\times 2000$. 
Table 1. Mean chiasma frequency, variances (between and within cells) and positional distribution of chiasmata

\begin{tabular}{lccccc}
\hline & Alas. & Win. & King. & Amer. & Lyon \\
\hline No. of cells obs. & \multicolumn{1}{c}{. } & 14 & 14 & 12 & 8 \\
Mean chiasma freq. per cell & 30.29 & 30.14 & 30.14 & 30.33 & 30.5 \\
Vx (b/w cells) & 0.11 & 0.14 & 0.05 & 0.12 & 0.06 \\
Vx (within cells) & 0.13 & 0.11 & 0.12 & 0.11 & 0.12 \\
Very-proximal (\%) & 87.38 & 97.16 & 52.13 & 97.25 & 93.44 \\
Proximal (\%) & 12.43 & 2.84 & 44.55 & 2.75 & 6.56 \\
Interstitial (\%) & - & - & 2.84 & - & - \\
Distal (\%) & 0.19 & - & 0.47 & - & - \\
Nov-VP (\%) & 12.62 & 2.84 & 47.86 & 2.75 & 6.56 \\
Achiasmate arm (\%) & 4.85 & 4.74 & 5.21 & 4.4 & 3.28 \\
\hline
\end{tabular}

Alas. $=$ Alaska, Win. $=$ Winterreuzen, King. $=$ King Richard, Amer. $=$ American flag, Non $\cdot V P=$ Non veryproximal, $\mathrm{Vx}=$ Variance.

Table 2. $2 \times 5$ contingency chi-square analysis with observed (above) and expected (below) frequencies of very proximal (VP) and non-very proximal (non-VP) chiasmata in five varieties of $A$. porrum

\begin{tabular}{lccc}
\hline \hline Variety & VP & Non-VP & Total \\
\hline Alaska & 450 & 65 & 515 \\
Winterreuzen & $(438.23)$ & $(76.77)$ & 211 \\
King Richard & 205 & $(31.45)$ & 211 \\
American flag & $(179.55)$ & 101 & 182 \\
Lyon & 110 & $(31.45)$ & 5 \\
& $(179.55)$ & $(27.13)$ & 8 \\
Total & $177.87)$ & $(18.2)$ & 152 \\
\hline
\end{tabular}

Chi-square value $(4 \mathrm{dn})=234.95, \mathrm{p}<.001$.

were found only in variety King Richard with frequency of only $2.84 \%$. Distally localized chiasmata were found only in varieties Alaska (0.19\%) and King Richard (0.47\%). This indicates that occurrence of proximal, interstitial and distal chiasmata is generally very low in A. porrum. Achiasmate arms were generally similar in all varieties and ranged from 3.28 to $5.21 \%$ (Table 1). The localization of chiasmata in the centromeric region gave a characteristic cross-shaped structure to the paired chromosomes at metaphase-I (Figs. 2a, 2b). A significant $\left(\chi^{2}{ }_{(4 \mathrm{~d})}=234.95 ; \mathrm{p}<0.001\right) 2 \times 5$ chi-square analysis on chiasma distribution (Table 2$)$ indicates that chiasma localization pattern between varieties is not independent. It has previously been observed that chiasmata are not randomly distributed between cells (Jones 1967), between bivalents (Haldane 1931) or within bivalents (Mather 1938). Each bivalent must normaly have at least one chiasma (Mather 1933). There is a great deviation in chiasma distribution within bivalents between species because it may be highly localized (Allium fistulosum and Allium porrum, Levan 1933, 1940 respectively) or distally localized (rye, Darlington 1933). The proximal distribution of chiasmata is thought to be a gene controlled phenomenon in leek (Gohil and Koul 1977). Chiasma frequency and distribution in combination with major gene control (Parker 1975, Tease and Jones 1976) have been shown to be under polygenic control (Rees 1961, Rees and Dale 1974, Karp and Jones 1983). It is believed that two different control systems are involved in the determination of chiasma frequency and distribution (Jones 1967). 
Table 3. Metaphase-I configurations in five varieties of $A$. porrum

\begin{tabular}{lccccc}
\hline \hline Observations & Alas. & Win. & King. & Amer. & Lyon \\
\hline Total cells & 168 & 124 & 60 & 70 & 53 \\
16 IIs & 160 & 120 & 57 & 65 & 51 \\
15 IIs +2 Is & 7 & 4 & 2 & 5 & 2 \\
14 IIs + 1 IV & 1 & - & 1 & - & - \\
16 IIs (\%) & 95.24 & 96.77 & 95.16 & 92.86 & 96.23 \\
14 IIs + 2 Is (\%) & 4.17 & 3.23 & 3.33 & -14 & - \\
14 IIs+1 IV (\%) & 0.6 & - & 1.67 & - & - \\
\hline
\end{tabular}

Alas. = Alaska, Win. $=$ Winterruezen, King. $=$ King Richard, Amer. = American flag.
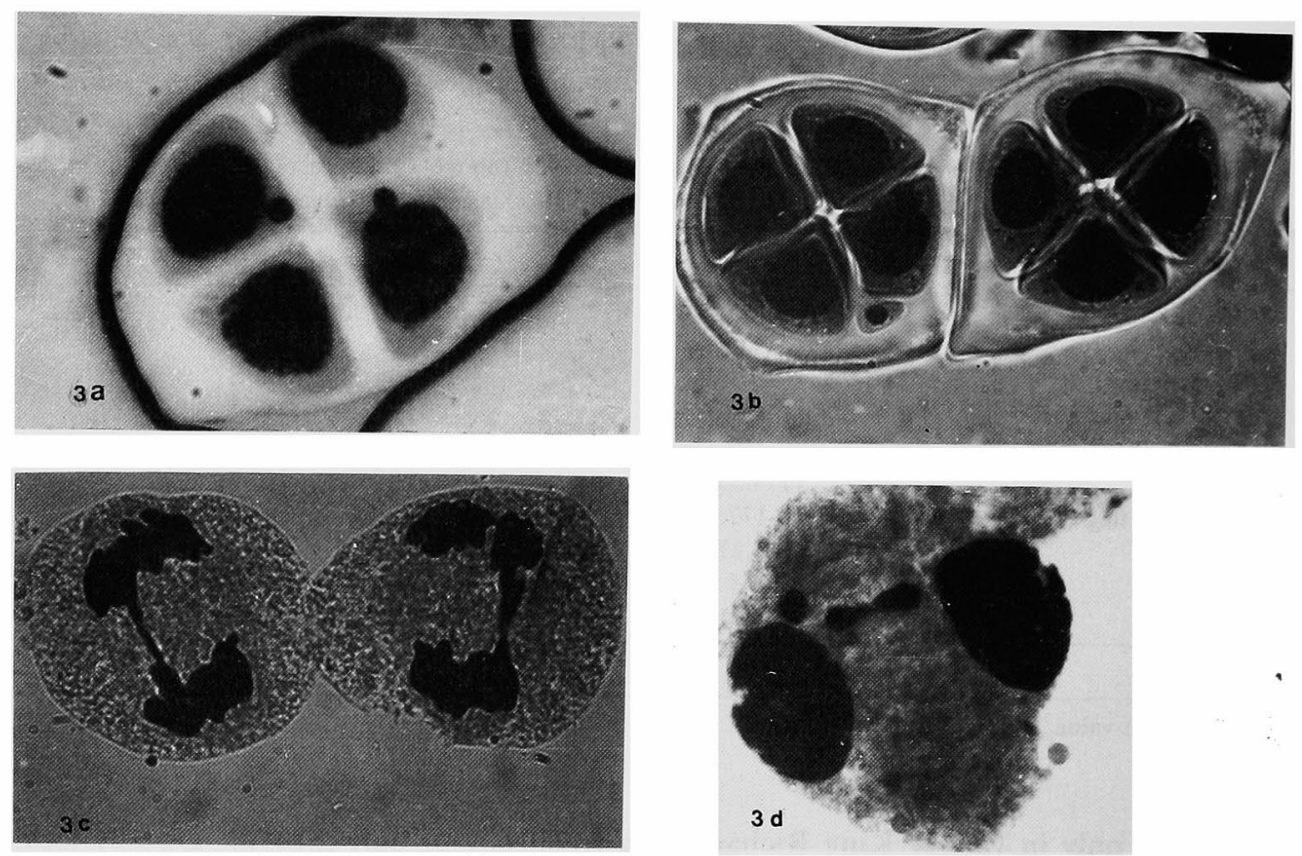

Fig. 3a-3d. 3a. Micronuclei at tetrad stage in A. porrum. 3b. Microcell in A. porrum at tetrad stage. 3c. Anaphase-I bridges in $A$. porrum. 3d. Telophase-I of $A$. porrum showing laggards.

\section{Metaphase I configurations}

Cells at metaphase-I usually showed normal bivalent configurations but univalents (Fig. 2c) and quadrivalents with distally localized chiasmata (Fig. 2d) were also found. Trivalents or other multivalents were not observed. Although A. porrum is a tetraploid quadrivalents were found only in 2 out of 475 cells. Earlier, such quadrivalents have also been found in $A$. porrum (Levan 1940) and in $A$ ampeloprasum (Koul and Gohil 1970). Univalents have also been reported in A. ampeloprasum (Koul and Gohil 1970). Metaphase-I configurations looked peculiar due to the localization of chiasmata near centromeric region. The bivalents were similar to those found in $A$. fistulosum. The frequency of univalents per cell ranged between $3.23-7.14 \%$ (Table 3).

\section{Micronuclei and microcells}

Micronuclei (Fig. 3a), microcells (Fig. 3b), bridges (Fig. 3c) and laggards (Fig. 3d) were among the major chromosomal abnormalities observed in many cells with varying frequency. 
Table 4. Frequencies of micronuclei and microcells in five varieties of $A$. porrum

\begin{tabular}{lccccccc}
\hline \hline Variety & Cell & 0 & \multicolumn{3}{c}{ Micronuclei (\%) } & \multicolumn{2}{c}{$\begin{array}{c}\text { Microcell } \\
(\%)\end{array}$} \\
\hline Alaska & 1000 & 91.4 & 5.6 & 2.8 & 0.2 & - & 4.4 \\
Win. & 777 & 89.7 & 1.8 & 4.4 & 3.4 & 0.8 & 2.3 \\
King. & 478 & 92.7 & 2.8 & 3.4 & 1.1 & - & - \\
Amer. & 485 & 83.7 & 9.2 & 4.3 & 2.7 & 0.5 & - \\
Lyon & 476 & 97.3 & 2.7 & - & - & - & - \\
\hline
\end{tabular}

Win. = Winterreuzen, King. $=$ King Richard, Amer. = American flag.

Maximum observed frequency of micronuclei was four per pollen mother cell. It is believed that chromosomal aberrations that appears at metaphase-I as breaks or exchanges give rise to acentric fragments, which transformed into micronuclei (Heddle and Carrano 1977, Boller and Schmid 1970, Matter and Jaeger 1975) (Table 4).

\section{Summary}

Data with respect to chiasma frequency, chiasma distribution, chromosome configurations at metaphase-I and frequecy of micronuclei and microcells at tetrad stage were collected from five varieties of $A$. porrum L. Mean chiasma frequency ranged from 30.14 and 30.5 per cell. Most of the chiasmata were either proximally or very-proximally localized. Cells at metaphase I usually showed normal bivalent configurations but univalents and quadrivalents were also observed.

\section{Acknowledgement}

I am grateful to the Association of Commonwealth Universities, UK for funding this research project and Dr. G. H. Jones, University of Birmingham for his constant guidance throughout this research project. I also thank Dr. Shafqat Farooq, NIAB, for her comments and suggestions on this manuscript.

\section{References}

Boller, K. and Schmid, N. 1970. Chemische Mutagenese beim Suger. Dos Knochenmark des Chinesischen Hamsters ab in vivo-Testsystem. Hamatologische Befunde nach Bchandlung mit Treminon. Human Genetik. 11: 33.

Currah, L. 1986. Leek breeding: a review. J. Hort. Science 61: 407-415.

Darlington, C. D. 1933. The origin of behaviour of chiasmata, VIII. Secale cereale (n, 8). Cytologia 4: 444-452.

and Wylie, A. P. 1956. Chromosome Atlas of Flowering Plants. London: Allen and Unwin.

Gohil, R. N. and Koul, A. K. 1977. The cause of multivalent suppression in Allium ampeloprasum L. Beitrage zur Biologie der Pflanzen 53: 473-478.

Haldane, J. B. S. 1931. The cytological basis of genetical interference. Cytologia 3: 54-65.

Heddle, J. A. and Carrano, A. V. 1977. The DNA content of micronuclei induced in mouse bone marrow by gamma-radiation: Evidence that micronuclei arise from acentric chromosomal fragments. Mutat. Res. 44: 63.

Jones, G. H. 1967. The control of chiasma distribution in rye. Chromosoma 22: 69-90.

Jones, H. A. and Mann, L. K. 1963. Onions and Their Allies. Leonard Hills Books.

Kadry, A. and Kamel, S. A. 1955. Cytological studies in the tetraploid species Allium kurrat Schweinf and A. porrum L. and their hybrids. Svensk. Bot. Tidskr. 49: 314-324.

Karp, A. and Jones, R. N. 1983. Cytogenetics of Lollium perenne. Part 2. Chiasma distribution in inbred lines. Theor. Appl. Genet. 64: 137-146.

Koul, A. K. and Gohil, R. N. 1970, Cytology of the tetraploid Allium ampeloprasum with chiasma localization. Chromosoma 29: 12-19. 
Levan, A. 1933. Cytological studies in Allium. IV. Allium fistulosum. Svensk. Bot. Tids. 27: 211-232.

1940. Meiosis of Allium porrum, a tetraploid species with chiasma localization. Hereditas 26: 454-462.

Mather, K. 1933. The relationship between chiasmata and crossing over in diploid and triploid Drosophila melanogaster. J. Genet. 27: 243-259.

1938. Crossing over. Biological Review 13: 252-292.

Matter, B. E. and Jaeger, I. 1975. Premature chromosome condensation, structural chromosome aberrations, and micronuclei in early mouse embryos after treatment of paternal postmeiotic germ cells with triethylenemelanine. Possible mechanisms for chemically induced dominant-lethal mutations. Mutat. Res. 33: 251.

Murin, A. 1964. Chromosome study in Allium porrum L. Caryologia 17: 575-578.

Nybom, N. 1947. Accessory chromosomes in Allium. Hereditas 33: 571-572.

Parker, J. S. 1975. Chromosome specific control of chiasma formation. Chromosoma 49: 391-406.

Rees, H. 1961. Genotypic control of chromosome form and behaviour. Bot. Rev. 27: 288-318.

— and Dale, P. J. 1974. Chiasmata and variability in Lolium and Festuca populations. Chromosoma 47: 335-351.

Tease, C. and Jones, G. H. 1976. Chromosome specific control of chiasma formation in Crepis capillaris. Chromosoma 57: $33-49$.

Vosa, C. G. 1966. Seed germination and B-chromosomes in the leek (Allium porrum). Chromosmes Today 1: $24-27$. 